
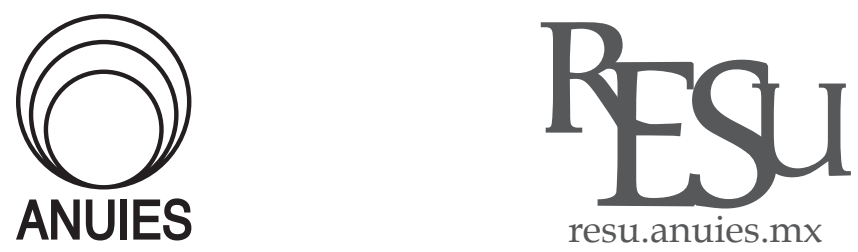

ARTíCULO

\title{
Irse de la universidad, regresar y persistir hasta el final: estudiantes peregrinos y sus sentidos sobre la escuela*
}

To leave the university, to return and to persist until the end: student's pilgrims and thier senses on the school

\author{
Enrique Paredes Ocaranza** y Claudia Lucy Saucedo Ramos \\ * Agradecimiento: gracias al apoyo y financiamiento del Consejo Nacional de Ciencia y Tecnología (Conacyt) se \\ pudo obtener los resultados de la presente investigación que forma parte del trabajo de tesis del programa de \\ doctorado en Psicología Educativa y del Desarrollo de la Universidad Nacional Autónoma de México (UNAM) y \\ cuyo primer autor realizó bajo la dirección de la Dra. Claudia Lucy Saucedo Ramos. \\ ** Facultad de Estudios Superiores Iztacala, UNAM / Instituto Nacional para la Evaluación de la Educación. \\ Correo electrónico: alep_ocaranza@yahoo.com.mx \\ Recibido el 06 de julio del 2017; aceptado el 27 de agosto del 2018.
}

\section{Resumen}

Este artículo atiende al planteamiento de la UNESCO de considerar como bien común a la Educación Superior, en un momento en que las Instituciones de Educación Superior están inmersas en procesos caracterizados por una progresiva mercantilización del conocimiento que condiciona el acceso a la financiación por posicionamiento en rankings internacionales, poniendo en riesgo el objeto de contribuir a un desarrollo sostenible en sus contextos. Mediante un particular análisis de aspectos relacionados con la Responsabilidad Social y la relación con los grupos de interés, se realiza una contribución a la reflexión teórica y a los desafíos para conceptualizar la Educación Superior como un bien común.

Palabras clave: Trayectorias Escolares; Identidad; Recorridos Escolares; Estudios Socioculturales; Estudiantes Universitarios 


\begin{abstract}
From a sociocultural approach we analyze the reasons that students of a private university offered us to explain the senses that they built around their school routes: their school dropouts, returns and permanence in the same. We interviewed eight psychology students from a private university who talked about themselves by positioning their identities in different ways, in situations of stress between contexts of practice or making choices of life. We conclude that the students have articulated a sense of schooling and in consequence they have managed to persist in school until they finish their studies.
\end{abstract}

Keywords: School Trajectories, Identity, School Trip, Sociocultural Studies, University Students

\title{
Introducción
}

$\mathrm{D}_{\mathrm{ras}}$ esde un enfoque sociocultural, en el presente trabajo analizamos las razones que los estudiantes de una universidad privada nos ofrecieron para explicar los sentidos que construyeron en torno a sus recorridos escolares: sus abandonos de la escuela, retornos y permanencia en la misma. Se trata de estudiantes que han abandonado la universidad en diferentes momentos de sus vidas, que priorizaron otras actividades y que, a fin de cuentas, decidieron regresar a estudiar y terminar lo que dejaron inconcluso. Son adultos que han desarrollado una reflexividad sobre sus vidas, sus relaciones familiares, sus empleos y sus proyecciones a futuro, y que sólo encontraron en universidades privadas la posibilidad de dar cierre a sus recorridos escolares:

La investigación sobre alumnos y estudiantes a últimas fechas nos ofrece un panorama alentador porque conocemos sus experiencias y sentidos en torno a la escuela. Sabemos que estudiar es un referente central en las familias mexicanas y sus hijos, y que la expectativa de cubrir cada vez un mayor número de años de escolarización alimenta el deseo de "llegar a ser alguien en la vida". Sin embargo, de cada 100 alumnos de estratos bajos en 2010, sólo 10 lograron terminar la universidad (Solís, 2014). Las razones que se aducen para el abandono escolar son diversas: necesidad de trabajar, disgusto por la escuela, embarazo temprano, entre otros. El abandono escolar ocurre, sobre todo, en el tránsito de la escuela secundaria al nivel medio superior. Los alumnos que permanecen estudiando han resistido la lógica institucional de las escuelas, el enciclopedismo de los curricula, la escasa relación entre conte50 
nidos académicos y su vida cotidiana; y, en el tránsito al nivel medio superior muchos se desaniman porque no logran superar el filtro del examen único de conocimientos y no obtienen un lugar en los bachilleratos considerados de prestigio que darían el pase automático a universidades públicas. Para ellos el mundo adulto se abre paso y la escuela queda atrás.

¿Qué pasa con los pocos alumnos que logran avanzar hasta la universidad a pesar de las adversidades? Entrar a la universidad no es garantía de permanencia ni de conseguir una trayectoria lineal escolar. Los estudiantes que están en la universidad pero que reprueban, desertan uno o varios semestres, y después regresan, tienen bajas calificaciones, terminan pero no se titulan, alteran las estadísticas de eficiencia terminal de las instituciones. Precisamente Velázquez (2007) analizó la condición de estudiantes de preparatoria que habían tenido diferentes recorridos escolares. Esta autora clasificó las trayectorias en continuas (cursar en tiempo y forma) y de interrupción; al conjugar estos dos elementos tenemos un panorama más amplio sobre quiénes son los estudiantes que extienden, retrasan, pausan, abandonan y retoman sus estudios. Así, al referirse a trayectorias de interrupción la autora encontró dos tipos: unirregresionales y multirregresionales, consistentes en un movimiento de vaivén porque los estudiantes van y regresan de una escuela a otra y alargan su permanencia/vínculo con la escuela, ya sea en la misma institución o en otra. Se trata de estudiantes "peregrinos" que en su recorrido a través del tiempo y en distintas instituciones no abandonan su expectativa de terminar los estudios de nivel medio y medio superior.

La investigación realizada con jóvenes estudiantes mexicanos ha mostrado que ser joven y ser estudiante implica estar en la escuela no sólo para estudiar sino para recrear, innovar y enriquecer sus identidades juveniles. Así, por ejemplo, Hernández (2006) al describir dos grandes núcleos o mundos en el que se desenvuelven los preparatorianos, encontró que las actividades de estudio y la vida juvenil están mediadas entre sí. Un desajuste en estos dos núcleos tiene como consecuencia arrastrar problemas académicos y eventualmente desertar. Para Guerrero (2006) este desvío de la escuela se origina por experimentar una situación detonante que propicia el alejamiento de lo académico, pero no de la escuela. Llega a suceder que el desajuste ocurre porque algunos alumnos no saben cómo manejar su libertad durante el bachillerato, y ello se ve reflejado en ausentismo, reprobación, mal comportamiento, entre otros. Al haber experimentado una trayectoria discontinua, muchos de estos estudiantes vivieron una reflexión profunda sobre su curso de vida: un turning point. En otras palabras, son aquellos momentos significativos, experiencias acumuladas, que originan una deliberación profunda sobre la vida; implica madurar, y a veces se traduce en un viraje en la trayectoria, un regreso, un deseo por terminar la escuela. 
Aunque ocurre tanto en escuelas públicas como en privadas, generalmente los peregrinos son los estudiantes de las públicas porque terminan saltando al ámbito de las escuelas privadas en el nivel universitario. Por consiguiente, también es oportuno hablar de escuelas expulsoras y de escuelas receptoras. Para Andión (2007), dejar de concentrarse solamente en la educación pública implica un paso que permite conocer algunos rasgos de escuelas privadas enfocadas a atender a estudiantes peregrinos.

En el nivel universitario los estudiantes también tienen que combinar sus vidas juveniles y sus estudios. Empero, la investigación ha demostrado que también están enfocados a lograr identidades escolarizadas acordes a la institución (pública o privada) en la que se encuentran, a la carrera que cursan o al tipo de estudiantes que son. Muchos estudiantes universitarios logran permanecer en la escuela gracias a que también son trabajadores. Al respecto, Guzmán (2007) encontró que varios estudiantes habían laborado en empleos económicos-administrativos: un primer grupo lo hizo por la aportación que les brinda el trabajo en su desarrollo personal, y el ganar dinero quedaba en segundo plano; el segundo grupo lo hizo por necesidad, y el empleo se tradujo para ellos en combinar su tiempo de estudio y de descanso.; y también estuvieron quienes trabajaron por "hacerlo" y no definía ni sus tiempos, ni ritmos de vida. Un dato interesante es que para todos ellos la escuela tiene un valor prioritario, pero no por ello dejan a un lado su vida laboral. Rentería (2012), a su vez, menciona que la idea de autorrealización y de desarrollo personal está ligada a la profesionalización, en otras palabras, los estudiantes entremezclan los significados de su vida juvenil, sus relaciones de pareja y el trabajo con ser aprendices en una carrera.

Cuando la persona no encaja con el imaginario o perfil institucional del estudiante promedio, las dificultades para concluir una carrera aumentan. Matus (2010) constató la ardua labor de identificación de varios estudiantes indígenas que intentaron acoplarse a los ritmos, compañeros, maestros y modos de ser marcados por el contexto institucional, sin embargo, los resultados fueron poco favorables, ya que generalmente presentaron trayectorias fragmentadas y recorridos caracterizados por dejar de estudiar por un lapso de tiempo.

Al referirnos a los estudiantes con intenciones de retomar sus estudios, encontramos detalles interesantes. Regresar a estudiar supone acoplarse a la institución por diversos senderos escolares y extraescolares. No es una cuestión meramente socioeconómica, se desarrolla también el proceso de construir una identidad de estudiante universitario y de profesionista. Cuando el alumno no logra transitar a una nueva identidad en los primeros semestres, es probable que presente desapego a la institución y paulatinamente abandone la escuela o configure un nuevo proyecto. Debemos agregar que, en 
muchos casos, los estudiantes escogen una institución o carrera por ser la única que los acepta, es decir, no es su primera, ni su segunda opción, sino de las últimas, lo cual genera dificultad para construir una identidad profesional (Barbosa, 2008). Respecto a los estudiantes con intenciones de regresar a estudiar podemos ubicarlos en distintas modalidades de estudio; su forma de estar en la escuela es distinta al estudiante con una trayectoria continua. Así, por ejemplo, Mata (2009) comparó las vivencias de uso del tiempo de estudiantes universitarios inscritos en sistema abierto con uno escolarizado. Para los primeros, organizar sus tareas representaba una dificultad porque el tiempo de estudio se superponía a las horas de trabajo, a la familia y otras actividades de importancia; unos minutos eran preciosos porque buscaban rescatar la mayor cantidad de tiempo para la escuela. Los de sistema escolarizado, por su parte, no se veían envueltos en esta necesidad.

El abandono y el fracaso escolares son temas complejos. Saucedo (2007), en su estudio con familias de cohortes de trabajadores del ferrocarril, encontró una heterogeneidad de trayectorias educativas, ya que en una misma familia había quienes tenían estudios universitarios y quienes sólo tenían la primaria o la secundaria. Los hijos con menor escolaridad dijeron que abandonaron la escuela por su voluntad y justificaban que prefirieron trabajar, casarse o continuar con su vida juvenil. También argumentaron que no se sentían capaces de continuar aprendiendo lo que se les enseñaba en la escuela, pero como adultos retomaron los significados que sus padres les habían ofrecido en torno a la escuela y lamentaban no haberla concluido. Suponían que tendrían mejores empleos si hubieran logrado una mayor certificación escolar, pero encontraban difícil regresar a estudiar porque tenían obligaciones laborales y familiares. Así, regresar a estudiar es una meta que no cualquiera se propone y logra, de ahí que sea importante conocer las experiencias de los estudiantes peregrinos, tanto de vida como en torno a lo escolar.

En el presente trabajo nos proponemos analizar las narrativas de ocho universitarios que nos ofrecieron hablar de sus trayectorias escolares. Nos interesó entender los sentidos de vida que los llevaron a dejar la escuela en determinados momentos y cómo se plantearon regresar a estudiar. Se trata de estudiantes universitarios que encontraron como opción de regreso una universidad particular con cuotas de acceso y permanencia de bajo costo. Ello les permitió no sólo acomodar sus horarios laborales, familiares y de tiempo libre, sino también sus ingresos económicos para costearse los estudios. Así, el interés analítico estuvo orientado a conocer e interpretar sus narraciones sobre el peregrinaje que realizaron para posicionarse como estudiantes a punto de terminar la universidad y cómo esto impactó en aspectos identitarios. 
Para llevar a cabo esta investigación partimos de un enfoque sociocultural que nos permitió analizar las narrativas de los estudiantes como actos de significado (Bruner, 1999) y a partir de las cuales los estudiantes elaboraron visiones importantes sobre sí mismos y sobre el valor de la escuela en sus vidas.

\section{Consideraciones conceptuales}

Desde un enfoque sociocultural nos posicionamos en el marco de análisis de la Psicología narrativa (Bruner, 1999). Entendemos que cuando las personas narran hacen uso de instrumentos culturales para recrear y dar sentido a aquello que vivieron. Sus narraciones no son una "ventana" para asomarnos a las circunstancias en las que estuvieron, sino una interpretación de lo acontecido. Ya Bruner (2004) indicó cómo las personas emplean géneros narrativos para dar cuenta de lo que se vive y de la posición de la persona en la historia contada. Cada quien puede narrarse como héroe, villano o víctima de la historia. La historia tendrá secuencias, descripciones, giros imprevistos, de acuerdo a la reconstrucción emocional y cognitiva que en el momento de narrar la persona esté movilizando. Narrarse supone poner al Yo como múltiple, nos dice Bruner (1999), porque siempre estamos participando en distintos contextos y con diferentes personas, de modo que no somos idénticos en cada momento sino que estamos "distribuidos" en tiempo, espacio, relaciones sociales. No obstante, asumimos la noción de persona planteada por Pérez (2014), según la cual toda experiencia de vida integra emoción, cognición, acción de manera indisoluble y siempre situada en contextos de práctica sociocultural. Justamente las narraciones les permiten a las personas pensarse y presentarse ante los otros de manera unificada, como determinado tipo de individuos, a pesar de que sus participaciones sean diversas en distintos contextos socioculturales.

Desde un enfoque sociocultural entendemos también que gracias a la participación que cada persona tiene en distintos contextos sociales de práctica (familia, escuela, trabajo, etc.) logra recorridos cotidianos en los que se apropia y usa diversos recursos culturales y materiales (lenguaje, historias, objetos) para constituirse como persona. Al mismo tiempo, la persona articula de manera dinámica los contextos en los que participa, llevando y trayendo efectos de uno a otro (Dreier, 1999). Por ejemplo, algo que se aprendió en un contexto familiar puede ser usado en uno escolar para darle sentido a estudiar "echarle ganas para ser alguien en la vida"; una práctica que resultó ser útil para la socialización en el barrio es introducida por los jóvenes en la escuela para recrear y dotar de diversión a las clases "llevarse y aguantarse", 
o bien, una práctica que los niños aprendieron en la escuela pueden llevarla a casa (el gusto por la lectura).

Cada día la cotidianeidad se construye a partir de recorridos y de articulaciones entre los distintos contextos. También al paso del tiempo hay recorridos. Los estudiosos de la vida de los estudiantes en las escuelas optaron por la noción de recorrido más que por la de trayectoria escolar. La segunda daba idea de un inicio, una secuencia de pasos más delimitados y el arribo a un punto esperado (Weiss, 2012). En cambio, la noción de recorrido escolar nos habla de momentos en el tiempo no del todo prefigurados, sobre todo cuando se trata de recorridos escolares no lineales. Como se mencionó, los recorridos escolares son diversos, con entradas y salidas de la escuela, cambios de una a otra, tiempos de espera, tiempos de abandono y regresos. El peregrinaje escolar es también una noción que nos permite conocer a los alumnos que van de una escuela a otra y, en última instancia, sus procesos identitarios se encuentran en una constante reelaboración para pensarse, sentirse y actuar en relación con lo escolar. Como adjetivo, el término peregrino se refiere a la persona que va por tierras extrañas y que encuentra dificultades en dicho recorrido.

Cuando una persona se narra y busca dar cuenta de cómo ha sido su vida al paso del tiempo, ofrece una versión de sí misma, una identidad narrada. Desde un enfoque sociocultural asumimos la noción de identidad narrada como el resultado que la persona logra a partir de las narrativas que emplea para dar cuenta de quién es. La narración es la vía, la herramienta y la fuente de articulación de la identidad. Sobre el tema, Brinkmann (2008) señala que la identidad es un constante diálogo con el sí mismo fundamentado en lo moral y gestado desde distintos niveles de interpretación (social o individual). La articulación de la narración no siempre es explícita, hablada, sino muchas veces hay aspectos implícitos poco claros y necesarios de dilucidar. Seguir la narración lleva a conocer los pasos que tomó una persona para descubrir en quién se convirtió, como llegó allí y hacia dónde va.

De acuerdo con lo anterior, en la presente investigación analizamos los recorridos escolares de estudiantes universitarios que narraron las decisiones que tomaron ya sea para dejar la escuela, regresar a estudiar, cambiar de escuela o permanecer hasta terminar en la última opción escolar en la que los ubicamos.

\section{Contextualización}

Los participantes estaban inscritos en el último año de la carrera de Psicología de una universidad privada catalogada como de absorción de la deman- 
da (De Vries, 2005). En su mayoría, la matrícula de este tipo de escuelas está conformada por quienes intentaron acceder a la educación pública superior sin éxito (Gladys, De la Paz y Gil, 2007). La clasificación de absorción de la demanda tiene un problema, no distingue del todo a las universidades particulares fundadas a principios del siglo xx y las que surgieron casi espontáneamente de la nada. Estas últimas, por lo general, albergan a aquellos estudiantes que estuvieron inscritos en una universidad pública, abandonaron la escuela y posteriormente retomaron sus estudios. Por tales motivos se propone el término universidad emergente para designar al contexto donde finalizaron sus estudios y usaremos el nombre Universidad Formativa (UF) para referirnos a la escuela en la que se encontraban inscritos los alumnos que participaron en la presente investigación.

A cada participante se le invitó a narrar su recorrido por las distintas escuelas donde intentó formarse. Las entrevistas se llevaron a cabo fuera de la universidad emergente, en cafeterías, parques y bibliotecas. Se empleó una grabadora de voz, se transcribieron los datos y realizamos un análisis de contenido.

Tabla 1

Descripción general de los participantes

\begin{tabular}{ccccc}
\hline Participante & Empleo & Edad & Estado civil & $\begin{array}{c}\text { Intentos de terminar la } \\
\text { universidad }\end{array}$ \\
\hline Alberto & Administración & 45 & Viudo & 2 \\
\hline Arturo & Ingeniero en computación & 36 & Casado y con hijos & 2 (segunda carrera) \\
\hline Jenny & RH & 32 & Madre soltera & 6 \\
\hline Faby & Instancia infantil & 38 & Casada y con hijos & 2 \\
\hline Mauri & & 31 & Madre soltera \\
\hline Diana & Dando talleres de estimulación & 28 & Casada y con un hijo & 2 \\
\hline Leo & temprana & 35 & Soltero \\
\hline Deyanira & Oficina & 29 & Casada y sin hijos \\
\hline
\end{tabular}

Como mostramos en la tabla 1, tres de nuestros entrevistados habían tenido un recorrido caracterizado por una serie de intermitencias entre entrar a una carrera, dejarla y retomar posteriormente la universidad en otra escuela hasta llegar a psicología en la Uf. Uno de ellos se demoró al cursar el nivel medio superior y luego entró a UF sin periodos de suspensión. Uno más concluyó una primera licenciatura y 20 años después se propuso entrar a estudiar psicología. La mayoría se encontraba trabajando y seis de ellos tenían hijos. Según contaron, llevaban una vida acelerada, con poco espacio para el descanso y la recreación; en general, se veían cansados y descuidaban sus activi- 
dades laborales. El periodo intermitente, que supone peregrinar por distintas universidades, puede durar entre dos y 20 años, hasta que alcanzan cierta estabilidad gracias a que logran ajustar sus horarios y participaciones entre sus múltiples actividades. En este punto, ya han construido una postura de persistencia escolar y tarde o temprano van a alcanzar su meta de terminar la universidad. En general, su edad oscila entre los 25 y 40 años, algunos ya son padres o comienzan a serlo.

A continuación analizamos los relatos en torno a sus recorridos hasta la universidad en la que se estabilizaron.

\section{Alejarse de los estudios universitarios}

La mayoría de los participantes se describieron hacia el pasado como buenos estudiantes y con intenciones de continuar estudiando. Su identidad como estudiantes se encontraba afianzada porque inicialmente se inscribieron en alguna carrera de su elección y empezaron a acudir a sus clases. Sin embargo, nos relataron circunstancias de vida que los llevaron a dejar la escuela y a asumirse como una persona distinta, con una identidad diferente a la de estudiantes. Por ejemplo, Arturo dejó de ser estudiante de tiempo completo para cumplir con su papel de padre y responsabilizarse del sustento familiar:

Yo estaba en administración, a mí me gustan mucho los números, entonces estudié estadística y cálculo, me casé y todo fue muy complicado, intenté seguir estudiando, pero la cuestión económica la verdad se me complicó. Entonces tuve que dejar esa situación como tal, dejarla, y decir: "un stand by".

Arturo se identificó como un estudiante gustoso por el conocimiento en la carrera que había elegido. Nos explicó que aunque no tenía la intención de casarse, su novia quedó embarazada y eligió formar una familia con ella. Recuerda que su situación de vida no era fácil y no pudo combinar los estudios con su condición como empleado y padre de familia. Pero desde el inicio se planteó no un abandono escolar sino una pausa, aunque ello no fue algo fácil:

Y obviamente mis papás no se enojaron, pero dijeron: "todo lo que has hecho, ¿qué onda?", y yo me decía: “iqué pasó?"

Según explicó, él había sido muy buen estudiante durante la preparatoria, se definió como muy cumplido y con buenas calificaciones, de modo que estudiar era una prioridad en su vida. Desde su perspectiva y la de sus padres, el embarazo fue un suceso que alteró la noción que se tenía de él. Un suceso imprevisto implica que la persona debe hacerse cargo de su nueva condición 
de vida. Se vuelve prioritario reinterpretar quién es, entrar en un proceso de reelaboración identitaria a partir de los nuevos contextos de participación en los que se ubica. En el caso de Arturo, empezar a trabajar y formar una familia:

Tomé una decisión muy rápida, no me arrepiento porque estoy muy feliz con mi esposa y mis tres hijos, pero son decisiones que llegan a cambiar tu cuestión académica. A mí me gustaba mucho, y yo decía: "no quiero dejar mi carrera, por mis papás, por el ideal mismo también".

El relato de Arturo destaca un idealismo construido desde una narrativa familiar, una autointerpretación con origen en el discurso de sus padres, de modo que podemos escuchar a sus padres a través de su voz. Su principal problema fue tener que elegir entre la escuela o mantener a su nueva familia. Él optó por su familia, aunque su identidad como estudiante era fuerte y le indicaba que debía y podía continuar sus estudios en el futuro. Su regreso a las aulas le tomó 15 años. Este caso da cuenta de una transición muy larga entre dejar de ser estudiante, ser padre de familia y empleado, hasta regresar a una combinación identitaria entre dichas formas de participación en distintos contextos.

Un embarazo imprevisto en el caso de las estudiantes mujeres también las coloca en condición de decidir si continuar o no en la universidad. Tal fue el caso de Diana, para quien no fue fácil permanecer estudiando. Ella transitó por dos bachilleratos hasta terminar el nivel medio superior, se inscribió en la UF, suspendió un tiempo por su embarazo y regresó a terminar:

A mí me daba mucha pena venir aquí a la universidad con mi pancita. Entonces me tuve que dar de baja temporal ¡Ay, no! Y otra vez fue dejar exactamente dos años (la escuela), los 9 de embarazo y el primer año de mi nena, (tiempo) en el que dejé de estudiar.

Diana destacó que no era posible vincular su embarazo con su condición de estudiante. La vergüenza fue como una crítica implícita a su embarazo, pero encontró como recurso una baja temporal que le permitía dedicarse a su maternidad para después regresar a estudiar. La articulación entre la maternidad y la condición estudiantil supone decidir continuar o pausar, negociar con la familia apoyos de distinto tipo y organizarse para el cuidado de los hijos a través de distintas estrategias. Diana optó por dedicarse a atender a su bebé y después regresar a la escuela. Con ello, colocó entre paréntesis su identidad como estudiante y puso en el foco de atención la de ser madre.

Otra situación personal que influye para el alejamiento de la escuela tiene que ver con la elección de una carrera que al paso del tiempo se vive como 
algo no deseado. Ian transitó por dos escuelas de nivel medio superior hasta terminar y posteriormente se inscribió en la carrera de pedagogía en la Universidad Pedagógica Nacional (UPN). Al darse cuenta de que no le agradaban las clases, ni estaba de acuerdo con los métodos de enseñanza de dicha universidad, Ian empezó a frecuentar la biblioteca de su escuela y a encontrarse con otros intereses de lectura:

Iba a la biblioteca. Encontré algunas cosas sobre Freud y sobre Young, Erich Fromm, y dije: "pues está padre, me llama la atención."

Ian se describió como un alumno que empezó a faltar a clases por el desinterés que sentía, y se visualizó como alguien que "había perdido el tiempo" ya que ni siquiera había disfrutado de fiestas, de alcohol, de relajo y menos de la carrera elegida. Por ello se cuestionó:

Y fue así como dije: “creo que les estoy viendo la cara a mis papás, ¿no?..." Ellos me daban semanalmente para mis pasajes. Ni siquiera me iba de borracho, ni siquiera tenía amigos en escuela, nada más iba a leer. (Y pensaba) Me estoy engañando a mí mismo porque mis materias están reprobadas y nada más les estoy quitando el dinero a mis papás. Mejor me voy a dar de baja".

Ian se ubicó como estudiante porque continuaba acudiendo a la escuela para leer en la biblioteca, pero no como el estudiante que cumple con los requisitos de la universidad porque reprobó materias y no entró a clases. Ponderó también el compromiso familiar como una condición que lo mantenía en la escuela y con el cual no estaba cumpliendo, y expresó abiertamente una crítica personal al aludir al autoengaño como una manera de no retribuir a sus padres ni a sí mismo. Él sostuvo una identidad parcialmente escolarizada, expresada en su gusto por acudir a la biblioteca a leer.

El recorrido escolar no termina con los estudios universitarios. Muchos estudiantes deciden continuar con posgrados o realizar una segunda carrera. En ese recorrido también se presentan tiempos de lejanía de lo escolar. Tal es el caso de Alberto, quien concluyó la carrera de informática en el Instituto Politécnico Nacional (IPN) y empezó a cursar administración en la misma institución. Podemos hablar de una identidad altamente escolarizada cuando la persona sostiene vínculos y participaciones importantes a lo largo del tiempo con instituciones escolares. Alberto se encontraba con un buen empleo e instalado en una segunda carrera cuando su esposa falleció. Dicho acontecimiento lo afectó sobremanera, de modo que entró en una crisis personal:

Estuve encerrado como unos seis meses, entre seis o siete meses aproximadamente. Tuve ese tiempo de depresión... y caí en esa depresión porque 
a mi pareja la habían atropellado y falleció. Entonces, ahí se quedó todo, se juntó la escuela, se juntaron complicaciones con mis profesores y con mis compañeros. Entonces fue por eso que decidí abandonar.

Alberto se refirió a ese período como algo difícil de enfrentar, entre el encierro y la depresión. Su relato es triste y se ubica en los conflictos que tuvo no sólo a nivel personal sino también en su situación escolar, de modo que se presentó el momento de dejar de lado la escuela por no poder conciliar las demandas que le hacían. Acontecimientos trágicos de vida colocan a los estudiantes en dificultades emocionales que no les permiten continuar con una cotidianeidad estudiantil favorable. 20 años después Alberto optó por continuar estudiando, esta vez psicología.

Los embarazos no planeados, el reconocer que no se había elegido la carrera adecuada y la depresión por la pérdida de un ser amado fueron las razones que varios de nuestros entrevistados adujeron para explicar su distanciamiento de los estudios universitarios. En sus reflexiones se cuestionaron su manera de proceder como estudiantes, tomaron decisiones respecto a cuál contexto de vida era más oportuno dedicarse (la familia), o bien, se reconocieron incapaces de continuar dado su estado de ánimo. Sus relatos incluyen el acompañamiento en sus recorridos por parte de sus familiares, ya sea sus padres, su esposa y sus hijos. De esta manera, la historia que cuentan no tiene un matiz individual, siempre es una integración de sí mismos con los otros que tuvieron un papel fundamental en las decisiones que tomaron para alejarse temporalmente de la escuela.

Los elementos identitarios que cada uno sostuvo en sus relatos también nos muestran que en un recorrido escolar es posible pausar, abandonar y reconsiderar los estudios. Nuestros entrevistados se tomaron diversos tiempos de espera, entre dos y 20 años, pero la parcela de identidad de acuerdo a la cual continuaban sintiéndose motivados para ser estudiantes ganó fortaleza y decidieron inscribirse en la Uf para estudiar la carrera de psicología hasta casi terminarla para el tiempo en el que realizamos las entrevistas.

\section{Dificultades para regresar a estudiar}

Según nuestros participantes, no fue fácil retomar sus estudios universitarios. Todos se consideraron como adultos que tenían responsabilidades diversas. En general hablaron de empleos con jornadas diarias largas, con tiempos de transporte y actividades familiares que reducían sus posibilidades de dedicar tiempo a los estudios. Entonces optaron por estudiar en la UF en el sistema sabatino. Para siete de nuestros participantes volver a establecerse 
en la universidad no fue un asunto sencillo. La mayoría realizó un primer intento de regreso, cursó un tiempo y desertó para volver a inscribirse y terminar. Jenny, por ejemplo, habla de sus ingresos y salidas de universidades:

Intenté en otros lados, en una escuela que es la Universidad de L, donde yo empecé a estudiar la carrera de informática. Me salí de informática, después me inscribí para psicología y en ese inter quedo embarazada y me tuve que volver a salir. Lo vuelvo a intentar posteriormente, años después, pero era complicado porque yo trabajaba en las noches.

En otros momentos de la entrevista Jenny se describió como una persona con gusto por los estudios. Consideró que la carrera de informática no le estaba gustando porque se enfermaba continuamente y eso fue una mensaje de que "no estaba haciendo bien las cosas", por lo que optó por descartar esa carrera y continuar en psicología. Sin embargo, se presenta a sí misma como cansada, con empleos que le dificultaban ir a la escuela y con un hijo al que debía atender. A pesar de ello, la vinculación con los estudios se mantuvo y logró entrar a la UF para avanzar en psicología. Estudiar en una universidad emergente implica para estos estudiantes dedicar la mayor parte de su tiempo en sus empleos, su familia y las actividades cotidianas, mientras que la escuela pasa a ocupar el tiempo que realmente tienen libre. La escuela no ocupa el primer lugar en su vida cotidiana, empero ellos buscan darle sentido para lograr permanecer en ella, como lo refiere Jenny:

De alguna manera en mi trabajo tengo mucha responsabilidad, entonces no puedes desatenderlo, y en las noches hago las cosas que me gustan de mis estudios, pero cuando es algo que realmente te gusta, pues lo disfrutas.

El acto de estudiar adquiere un valor de recreación, una distracción de la vida laboral y familiar: "hago las cosas que me gusta de mis estudios", es una estrategia personal. Adoptar esta narración sobre el tiempo libre y los estudios simboliza cómo entiende el estudiante su vida a través de los contextos. La escuela parece ser un hobby, una meta personal importante, una opción para alcanzarla durante el tiempo destinado para descansar. Lo anterior es la evidencia de una identidad de persistencia con base en el significado que le otorgó Jenny a estudiar y al tiempo libre.

Como estudiantes que tienen recorridos escolares intermitentes, el gusto por la escuela y la necesidad de persistir se presenta en distintos momentos para cada uno. Leo, por ejemplo, dijo que en la preparatoria sólo se dedicaba "al relajo", de modo que optó por terminar en preparatoria abierta, lo cual le costó mucho trabajo, pero que avanzó debido a una circunstancia difícil en su vida: 
¿Cómo llegué a idea de que tenía que estudiar? (Reflexiona y se toma un poco de tiempo para responder). Yo pienso que todo fue a raíz de que falleció mi hermana...

En el recorrido de vida, la escuela puede no tener importancia para una persona, o puede ir perdiéndola al encontrar más atractivo el mundo de la diversión juvenil, pero los giros se presentan para revalorar los estudios. Se trata del turning point al que hace alusión Guerrero (2006) y que supone una fuerte reflexión para reorientar la vida, particularmente hacia la escuela. Para Leo, la muerte de su hermana fue esa experiencia vital que le llevó a replantear su vida. En sus reflexiones vuelven a salir las voces de la familia interesada en que la escuela tenga un lugar significativo en su proyecto de vida:

Y ella era como mi mamá. Mis papás trabajaban, y en el tiempo en el que yo trabajaba, en mis descansos, yo estaba con ella, ella era la que me daba de comer, era la que me decía: "estudia".

La postura de persistencia y posteriormente de resistencia, ya fortalecida por la experiencia de fracaso y abandono o por una gran pérdida, en el caso de Leo enriquece y fundamenta una identidad de resistencia:

A raíz de que ella enferma y fallece fue cuando dije: "tengo que hacer algo". Fue cuando me cayó el veinte de que lo que estaba haciendo no estaba del todo bien, mis papás no me iba a durar para siempre, incluso fue cuando decidí meterme a estudiar y trabajar otra vez.

Parte de asumir esta postura de resistencia y persistencia lleva un proceso de reflexión, el comentario "como que me cayó el veinte", enuncia una visión de sí mismo con retos y obligaciones distintas. El mensaje simbólico de la hermana y la consideración al lugar que ocupa en su familia le llevaron a replantear la escuela como algo importante. Él buscó articular el empleo y la escuela y ha conseguido sostenerse en la uf hasta casi terminar la carrera de psicología en el momento de la entrevista.

Abrirse paso por la escuela representa para las personas con recorridos intermitentes un desafío personal. Ante la dificultad y la presión para acoplar los horarios laborales, escolares y familiares en una rutina, sin descuidar alguna de sus responsabilidades, las posturas de persistencia y de resistencia escolares son claves. Asumir una postura supone una visión de vida que las personas despliegan. En ella pueden presentarse como alguien luchador, exitoso, o bien que no pudieron conseguir lo que esperaban y ofrecen justificaciones al respecto. Nuestros estudiantes de la UF elaboraron posturas de persistencia (continuar estudiando a pesar de las dificultades) sostenidas en la resistencia personal (emocional, económica y social) para darle sentido a lo que hacían. 
Estas posturas no emergieron sólo durante la entrevista. Los propios estudiantes trajeron a colación las reflexiones que hacían en determinados momentos y en las que se hablaban a sí mismos sobre la persistencia que debían tener. Tal es el caso de Diana, que es madre, estudiante y trabaja ofreciendo talleres de estimulación temprana:

Ahora era como tiempo compartido entre mi nena, el trabajo y la escuela, pero yo decía: “iyo no sé cómo le hago, pero la acabo!”. Ahorita la tengo que acabar y a lo mejor me va a costar más trabajo porque pues el tiempo ya no es el mismo, ya no le dedicas el mismo tiempo.

Diana nos ofrece una visión de sí distribuida entre los principales contextos de su vida. Si bien su condición de madre es muy importante, ella habla de terminar también la escuela como un compromiso. La persistencia supone diferenciar las actividades que son primordiales de las que se les dedica más tiempo, pero se resalta el deseo de continuar. Se trata de una identidad en conflicto, con tensiones para elegir, pero con la claridad de que a pesar de las dificultades se mantiene la meta de terminar de estudiar.

Sin embargo, estos estudiantes que han persistido en sus recorridos de entradas y salidas de escuelas para finalmente establecerse en la UF, también resienten las dificultades para articular los distintos contextos de participación en los que se encuentran con sus condiciones de salud y de economía personal y familiar:

Cuando los profesores son muy estrictos y hay muchas tareas, y además el trabajo, llega el momento en que son demasiadas cosas. Creo que todos pasamos por esas etapas, te enfermas... Porque todos tenemos un límite en nuestra vida en cierta situación y la vida en ciertos momentos te dan esas crisis: crisis de dinero, de no tengo para mí colegiatura, de tengo que trabajar; en mi trabajo me está pidiendo mucho mi jefe, los profesores...

Arturo enfatiza las presiones que enfrenta y enmarca esta última como una condición de crisis en distintos sentidos. Él también acentúa la carga de trabajo tanto en la escuela como en su empleo, aunada a la tensión económica de cubrir su colegiatura. Muchos estudiantes de universidades emergentes pagan personalmente sus estudios y deben coordinarse para desplegar distintas identidades en la práctica: pareja, padre, empleado, estudiante. Con todo, ellos no están solos al tratar de cubrir sus metas. Vimos cómo el mensaje de una hermana fallecida tuvo un papel importante, también la alusión a los padres y su apoyo constante, o bien el valioso papel de una esposa, como relata Arturo: 
Yo le decía a mi esposa, quien terminó hace un año más o menos: “oye, me dejaron este tema, no seas mala onda y búscame en Internet sobre esta materia". Y yo hacía todo el análisis y ella me ayudaba con la información.

Arturo reconoce el apoyo de su esposa, pero no sólo en lo familiar sino en lo académico. Él se colocó como demandante de información, pero también como activo al afirmar que analizaba el material.

Estos alumnos, con recorridos escolares intermitentes y que están por concluir su carrera, enfatizaron las dificultades que tuvieron para regresar a estudiar, porque, aunque no es el centro de sus vidas, nunca perdieron el gusto y el interés por la escuela. Ellos tienen que ajustar tiempos y actividades para cumplir primero con sus empleos, familias, y al final dedicarse a lo escolar. Para fortalecer su resistencia llevan en sus pensamientos consejos familiares o consignas de motivación personal. Reconocen que es un periodo difícil y que pueden derivar en crisis, pero no desisten porque han aprendido a sostener su condición como estudiantes en y a través de contextos de vida altamente demandantes.

\section{Persistir hasta el final}

Dentro de la narrativa de resistir hasta concluir la universidad está presente el significado de tener una profesión. Aparentemente, los estudios siguen siendo símbolo de movilidad social y económica. Casi todos los participantes hablaron sobre las ventajas de terminar una carrera universitaria, pero mejorar sus ingresos no es el motivo principal por el cual lo hacen. En cada historia hay una justificación personal, un porqué de este interés. Estos motivos son el sustento de la resistencia escolar. Por ejemplo, después de darse un tiempo de ocho años, Faby vuelve a intentar ingresar a una universidad pública, ya lo había intentado al salir de la preparatoria, pero sin éxito. Ella relató que inicialmente sus intereses eran administración, derecho o informática. Sin embargo, consideró entrar a la UPN debido a su trabajo: era administrativa en una estancia infantil del Instituto de Seguridad y Servicios Sociales de los Trabajadores del Estado (ISSSTE) y pensaba que ser pedagoga le daba la posibilidad de obtener un mejor puesto y aumentar sus ingresos. Al no acoplarse a pedagogía en la UPN, Faby decide intentar con psicología.

Hice examen para la Pedagógica; en un principio quería pedagogía antes que psicología. Yo estaba como que enfocada a la pedagogía, porque esas dos profesiones son las más recurrentes en mi trabajo... La verdad no era lo que yo quería estudiar y entonces decidí psicología, y no volví a quedarme en la pedagógica... 
Faby situó la psicología como un medio para retomar sus estudios y desarrollarse en el ámbito laboral, y su permanencia escolar involucra evaluar lo más conveniente para ella. En síntesis, Faby no sólo pensó en estudiar algo de su agrado, sino que valoró la posibilidad de crecer laboralmente. Sin embargo, su intención por terminar una carrera tiene raíces en su familia. Al saber que su hermana terminó la licenciatura, Faby reflexionó sobre su vida:

Entonces cuando yo vi que ella estaba estudiando, dije: "yo tengo" (que estudiar), y fue algo que también me movió mucho: “yo tengo también que hacer algo". Te digo, yo tenía ese pendiente, pero cuando ella lo estaba haciendo dije: “¿qué camino tengo que seguir?".

En su relato Faby sostuvo parcelas de identidad que estaba negociando. Por un lado, su identidad como empleada que quería favorecer al obtener una formación acorde a su labor y, por el otro, se comparó con su hermana y quiso tomar su ejemplo. Así, volver a la escuela reproduce el tradicional sentido de superación personal y movilidad laboral, pero cada persona lo complementa al volverse a mirar para hacer sus elecciones de vida.

Como se ha dicho, esperar el momento adecuado para volver a intentarlo puede ser crucial. Regresando al caso de Alberto, tras la muerte de su esposa pospone reincorporarse a la escuela porque el nivel de exigencia en su trabajo era muy alto en ese entonces, pero al flexibilizarse, decide después de cinco años retomar sus estudios en la UF:

Era necesario viajar mucho en mi trabajo y entonces dije: "no, si ahorita me meto a la escuela no voy a poder con las tareas, con los horarios". Entonces decidí dedicarme a mi trabajo, darme tiempo para crecer...

Saber en qué circunstancias es más conveniente retomar los estudios es relevante para la permanencia; lo anterior refleja un componente estratégico en la postura de persistencia. Alberto reflexionó sobre su proceso de reingreso a la universidad; por su experiencia previa en la carrera de informática tenía una idea del ritmo de trabajo en la universidad. Al final evaluó su capacidad para participar adecuadamente en el trabajo y la universidad. Al decidir regresar, analiza las posibilidades, los horarios, el ambiente escolar:

También supimos que en fin de semana va la gente que generalmente trabaja, pues bueno, a lo mejor va gente que trabaja y va con otra mentalidad.

Alberto buscaba un espacio adecuado a sus horarios y su edad, un espacio donde pudiera enfocarse a estudiar y concluir otra carrera. Lo anterior representa una estrategia previa a la toma de decisiones, la persona busca una uni- 
versidad acorde a su estilo de vida y no tanto por el prestigio. Al retomar los estudios, estas personas evalúan sus opciones y lo planean. Tal es el caso de Deyanira que eligió una universidad emergente por el costo y los horarios:

Realmente estaba muy cara (otra universidad) y no la podía costear y dije: "necesito algo más bajo y más accesible", aparte ahí era de lunes a viernes, no había sabatinos. Tenía dinero ahorrado y dije: "con esto por lo menos puedo sobrevivir un poco en lo que consigo otro trabajo".

Deyanira había hecho exámenes para ingresar a otras carreras en tres ocasiones, hasta que pudo definirse por psicología. Ella contó que trabajó un tiempo en una zapatería y ahorró dinero para su inscripción y sus materias. Después fue su hermana, quien es profesionista, la que le ha ayudado para que continúe estudiando. En estas condiciones Deyanira transitó entre varias opciones escolares, empleos, el apoyo de su hermana y de su novio para calcular sus tiempos y posibilidades de permanencia en la universidad. Las narraciones de todos nuestros entrevistados se orientan, en diferentes momentos, a destacar el papel que jugaron en sus interpretaciones y decisiones, sus familiares más cercanos. Para Deyanira, su hermana siempre fue un referente importante porque quería ser como ella, de ahí que la escuela era el camino a seguir. Por otro lado, Mauri reflexionó sobre su posición de madre y en qué medida era importante ofrecerle a su hijo una imagen distinta:

Porque muchos proyectos que he empezado en mi vida no los termino, muchos, muchos, y dije: "esto es muy importante porque me va hacer crecer como persona y me va a servir, a lo mejor para ser autosuficiente económicamente y también porque quiero que mi hijo vea que su mamá estudió. Y que mi hijo vea que su mamá hizo algo por sí misma y que no se quedó nada más estirando la mano o aguantando malos tratos nada más por dinero"...

Mauri ofreció una reflexión en la que se jugaba su identidad como madre. Así, continuar en la Uf es parte de un proyecto de consecución de un título que permita un mejor empleo, a la vez que movilizar las nociones que tiene sobre sí misma y las visiones que se ofrecen a otras personas, principalmente familiares. Estas narrativas poseen historias personales y familiares que llevan a persistir en su afán por terminar estudios universitarios.

Permanecer en la escuela es una empresa para la cual nuestros entrevistados tuvieron que ensayar varias veces en distintas opciones educativas antes de quedarse en la UF en la carrera de psicología. También calcularon la distribución de sus tiempos para ubicarse en estudios sabatinos, y los costos que tenían que cubrir. Si bien pueden recibir apoyo de sus familias, estos estudiantes son adultos completamente responsables de su permanencia en la 
escuela. Las imágenes y voces de sus familias se plasman en sus reflexiones cuando agradecen el ejemplo de sus padres, la figura paterna que quieren lograr, el apoyo de la hermana. De acuerdo con lo anterior, la permanencia en la escuela no es una tarea que emprenden en solitario.

\section{Discusión final}

Nuestros entrevistados nos ofrecieron relatos en los que reflexionaron quiénes han sido en los últimos años. Los vínculos que dijeron tener con la escuela en distintos momentos nos permitieron llamarles peregrinos porque transitaron entre varias opciones educativas no sin dificultades. Las historias narradas ofrecieron una visión de sí mismos anclada a la escuela en diferentes intensidades, así por ejemplo hubo quien se definió como una persona muy segura de continuar estudiando a pesar de sus separaciones con la escuela; otros en cambio dijeron que sí habían pensado que su vínculo con los estudios estaba terminado después de concluir la preparatoria, pero se replantearon la importancia de la escuela al paso del tiempo.

Algunos participantes transitan de ser estudiantes a padres y a empleados. Su transición es precedida por una elección de vida que coloca entre paréntesis su identidad escolar. Esta elección se da a partir de intentar conjugar todas estas identidades de forma infructuosa. Otros adoptan una identidad parcialmente escolarizada (ir a la escuela, pero no entrar a clases) hasta darse cuenta que aludían al autoengaño. Están también quienes asumen una identidad altamente escolarizada, pero debido a un acontecimiento trágico o turning point (Guerrero, 2006) sufren una crisis emocional y deciden retirarse momentáneamente de la escuela. Alejarse de la escuela implica preguntarse ¿quién se es ahora? Para responderse se ubican en un nuevo espacio de autointerpretación, donde todavía terminar la universidad significa autorealizarse. Brinkmann (2008) ya ha hecho una férrea crítica al énfasis moderno por la autorealización en el mundo del consumo.

Precisamente ese deseo de autorrealizarse a través de los estudios, lleva a nuestros participantes a luchar por reintegrase a lo escolar. Al lograr afianzar otras identidades no escolares lo vuelven a intentar. Para ello deben vencer las dificultades económicas, familiares, laborales y de tiempo no sorteadas en sus intentos anteriores. Todo lo anterior nos da indicio de una etapa de planeación y de preparación de la cual germina la postura de resistencia y de persistencia escolar. De manera transversal la persistencia escolar atraviesa distintos aspectos; cabe destacar que no son procesos aislados ni lineales, sino que son construcciones que logran conjuntamente con los allegados. Pero incluso más que afirmarse, los participantes explícitamente se mani- 
fiestan como personas persistentes hasta el final, con un Yo persistente, y su postura se evidencia más a través de la narración de sus acciones y no por cómo se definen. Asumir una postura de persistencia les implicó vivir experiencias de "entrada y salida" de distintas carreras y universidades. Por los vínculos que dijeron tener con la escuela en distintos momentos, nos permitimos llamarles peregrinos. Al reflexionar sobre su propio recorrido, al usar estrategias y adoptar narrativas como el "yo tengo", lograron ajustar su vida cotidiana para permanecer estudiando.

Aunque los recorridos intermitentes de los participantes cumplen con algunas de las características de las trayectorias regresionales o fragmentadas (Matus, 2010; Velázquez, 2007), se diferencian en el sentido que otorgan a su recorrido: un ciclo o espera escolar y preparación, por ello empleamos el término de recorridos intermitentes. Cabe resaltar que, para algunos de los participantes, este recorrido inició en el nivel medio superior, mientras que para la mayoría se presentó en el nivel universitario. Además, nuestros participantes están ubicados en contextos altamente demandantes (familiar y laboral), lo cual los llevó a elaborar posturas de persistencia sostenidas en la resistencia personal (emocional, económica y social), es decir, aprendieron a sostener su condición de universitarios en una situación adversa. Esto no lo hubieran logrado sin apoyo, por lo que debemos destacar el papel decisivo de la familia en la permanencia escolar, no únicamente porque brindan sustento, sino porque proporciona una estructura compuesta por experiencias, significados y sentidos que forjan una postura vinculada a lo escolar.

En resumen, se ha hablado de tres aspectos elementales en los recorridos intermitentes de estos tipos de estudiantes: sus relatos, las posturas personales que lograron elaborar y las identidades múltiples que construyeron al transitar por distintos contextos de práctica: familiar, escolar y laboral (Bruner, 1999; Dreir, 1999, Pérez, 2014). El significado de abandonar los estudios de los participantes evolucionó hasta llegar a un punto de resignificación a través de sus experiencias de vida. El cambio en ellos se da desde la experiencia de irse y de regresar de la escuela y en modelos familiares narrativos e identitarios.

Las universidades emergentes, como la UF, se han constituido como oferta ante la demanda de educación para adultos trabajadores que desean obtener un título universitario. Mucho se habla de la baja calidad de estas universidades; se dice que emergieron sin tradición pedagógica que las sustente, que sus profesores no están capacitados del todo, y que la calidad en la formación profesional es baja (Gama, 2010). Sin embargo, para muchos estudiantes es la única opción de certificación escolar. Ellos logran adecuarse en tiempos, actividades laborales y familiares y en los recursos económicos que tienen para ingresar y permanecer en una universidad emergente. Vimos cómo en sus 
relatos hablaron de que buscaban que sus padres se sintieran orgullosos, o que sus hijos los percibieran como personas valiosas. Así, la Uf es un contexto de participación elegido y valorado en la formación profesional de nuestros entrevistados que les permitió cerrar sus ciclos de peregrinaje estudiantil. En sus relatos la persistencia por lo escolar se orientó hasta casi terminar la licenciatura en psicología, algo nada despreciable si tomamos en cuenta que las universidades públicas y las privadas de prestigio con frecuencia no están abiertas a las posibilidades de elección y de participación de estos adultos.

\section{Referencias}

Andión, Mauricio (2007). Sobre la calidad en la educación superior: una visión cualitativa. Red de Revistas Científicas de América Latina y el Caribe, España y Portugal, (50), 83-92.

Barbosa, Ariana Elizabeth (2008). La identidad profesional de los sociólogos. Tesis de Maestría en Ciencias Sociales. México D. F.: Universidad Nacional Autónoma de México. Recuperado de: http://conocimientoabierto.flacso.edu.mx/medios/tesis/machuca_ae.pdf

Brinkmann, Svend (2008). Identity as self interpretation. Theory and Psychology, 18 (3), 404-421.

Bruner, Jerome (2004). Life as Narrative. Social Research, 71 (3), 691-710.

Bruner, Jerome. (1990). Actos de significado. Más alla de la revoluación cognitiva. Madrid: Alianza Editorial .

De Vries, Wietse (2005). ¿Privado vs. Público? Revista de la Educación Superior, 135 (34), 7-9.

Dreier, Ole (1999). Personal Trajectories of Participation across Contexts of Social Practice. Outlines. Critical Practice Studies, 1 (1), 5-35. Recuperado de http:/ / documents.mx/documents/trayectoria-de-participacion-ole-dreier.html

Gama, Francisco (2010). Desarrollo de una tipología de las instituciones de educación superior privada en Jalisco. Revista de la Educación Superior, 39 (153), 65-84.

Gladys, Nancy, De la Paz, Manuel y Gil, Manuel (2007). De “¿cuál te pinta mejor?" a "¿para cuál te alcanza?": desigualdad e inequidad social en el acceso a la educación superior en México. Revista Electrónica de Investigación Educativa, 1 (9), 1-49.

Guerrero, María Elsa (2006). El punto de retorno: Una experiencia de estudiantes de bachillerato universitario. Revista Mexicana de Investigación Educativa, 11 (29), 483-507. Recuperado de: http://www.redalyc.org/pdf/140/14002908. pdf

Guzman, Carlota (2007). Experiencias e identidades de los estudiantes de nivel superior que trabjan . En Carlota Guzman y Claudia Saucedo (Coordinadoras), La voz de los estudiantes Experiencias entorno a la escuela (págs. 194-217). Barcelona: Ediciones Pomares. 
Hernández, Joaquín (2006). Construir una identidad vida juvenil y estudio en el CCH sur. Revista Mexicana de Investigación Educativa, 11 (29), 459-481. En http:/ / www.redalyc.org/articulo.oa?id=14002907

Mata, Margarita Beatriz (2009). El tiempo y los estudiantes del SUAFYL. Tesis de Doctorado en Pedagogía. México D. F.: Universidad Nacional Autónoma de México.

Matus, María Luisa (2010). El Caso de la Universidad Veracruzana Intercultural, región Selvas. Tesis de Maestrìa en Investigación Educativa. Veracruz: Universidad Veracruzana.

Pérez, Gilberto (2014). Persona como categoría integradora de una perspectiva sociocultural en psicología. Revista de Educación y Desarrollo, 31, 5-16. Recuperado de: http://www.cucs.udg.mx/revistas/edu_desarrollo/anteriores/31/31_Perez.pdf

Rentería, Irma Daniela (2012). Posibilidades de autorrealización: significados de la educación superior y proyecto de vida en estudiantes Universitarios de Tijuana. Tesis de Mestría en Estudios Culturales. Baja California, Tijuana. Colegio de la Frontera Norte. Recuperado de: http://www.colef.mx/posgrado/wp-content/ uploads/2014/03/TESIS-Renter\%C3\% ADa-D\%C3\% ADaz-Irma-Daniela.pdf

Saucedo, Claudia Lucy (2007). La importancia de la escuela en las experiencias de vida de los estudiantes: su valoración restrospectiva a través de relatos de vida. En Claudia Lucy Saucedo y Carlota Guzman (Coordinadoras), La voz de los estudiantes (págs. 71-69). Barcelona: Pomares.

Solís, Patricio (2014). Desigualdad social y efectos institucionales en las transiciones educativas. En Blanco, Emilio, Patricio Solís y Héctor Robles, coord. (2014), Caminos desiguales: Trayectorias educativas y laborales de los jóvenes en la Ciudad de México. México: INEE-El Colegio de México

Velázquez, Luz María (2007). Como vivo la escuela :oficio de estudiante y microculturas juveniles. Estado de México: Gobierno del Estado de México, Secretaría de Educación, Servicios Educativos Integrados al Estado de México.

Weiss, Eduardo (2012). Los estudiantes como jóvenes. El proceso de subjetivación. Perfiles Educativos, 34 (135), 134-148. Recuperado de: http:/ / www.revistas.unam.mx/index.php/perfiles/article/view/29175 